\title{
Do Obesity and Vitamin D Correlate with Each Other: A Mini Review
}

\author{
Raouf Afifi* \\ International Management-Health Services and Research Institute, Indianapolis, Indiana, USA
}

Submission: March 03, 2019; Published: June 26, 2019

*Corresponding author: Raouf Afifi, International Management-Health Services and Research Institute, ITM-HS\& Research Institute, 13835 Azalea Circle 201, Tampa Fl. 33613, Indianapolis, Indiana, USA

Abstract

Obesity is a chronic health problem inflecting most today's communities. There association between obesity and an array of subsequent chronic health problems is a well-established. Now that vitamin D deficiency has also been linked to obesity, a review of the relationship between obesity and vitamin D including mechanisms, determinants, and severities may be rationalized. Understanding the association between the two conditions helps update available preventive approaches and provide opportunity for a better protection of risk population groups.

Keywords: Obesity; Vitamin D deficiency; Cardiovascular disease; Diabetes mellitus; Hypertension; Fat cells; Cariometabolic; Nutritional derangements; Dietetic; Behavioral and metabolic factors

Abbreviations: CVD: Cardiovascular Disease; HTN: Hypertension; DM: Diabetes Mellitus; VDD: Vitamin D Deficiency; PA: Physical Activity; WHO: World Health Organization; BMI: Body Mass Index; WC: Waist Circumference; WHR: Waist-Hip Ratio; BF: Body Fat; PIA: Physical Inactivity; FM: Fat Mass; VAT: Visceral Adipose Tissue; DEXA: Dual-Energy X-Ray Absorptiometry; OJ: Orange Juice; IL: Interleukin; TNF: Tumor Necrosis; FFAs: Free Fatty Acids; PTH: Plasma Parathyroid Hormone; FPG: Fasting Plasma Glucose

\section{Background}

The burden of obesity and associated health consequences, particularly cardiovascular disease (CVD) and other cardiometabolic diseases such as hypertension (HTN) and diabetes mellitus (DM) is grave [1]. Vitamin D deficiency (VDD) has been incriminated in some fat cells accumulation mechanisms [2]. Prevention, especially lifestyle modification is critical to ameliorate risks leading to extra weight gain and early detection of cariometabolic and nutritional derangements, VDD.

\section{Methods}

A focused search utilizing quality resources, e.g., PubMed, Ovid Medline, Cochrane library, and Google Scholar would be used to examine information and arguments about obesity and VDD relationship, tracking the development of knowledge about obesity-VD complex would be performed. For journal articles, only ISSN numbered periodicals and studies with representative and reliable sampling techniques were included.

\section{Literature Review}

With the change in the world's dietary and physical activity (PA) pattern, the world populations, even children are growing fatter [3]. In 2014, more than 1.9 billion adults 18 and older were overweight, including 600 million obese. These figures represent $39 \%$ and $13 \%$ of adult population, respectively [4].

\section{Obesity assessment}

The World Health Organization (WHO) defines increased body weight in terms of body mass index (BMI), as MBI $25 \mathrm{~kg} / \mathrm{m} 2$ = overweight and BMI $30 \mathrm{~kg} / \mathrm{m}^{2}=$ obese [4]. Other anthropometric measures are used to assess weight, such as waist circumference (WC) and waist-hip ratio (WHR) [5,6].

Several physical, dietetic, behavioral, and metabolic factors have been incriminated in the development of obesity, including fat cell theory; for an increased proliferation of fat cells and adipose tissues during infancy and childhood predisposes to adulthood obesity $[7,8]$. Both the heightened adipose tissue mass and metabolic changes of obesity increase the risk of the chronic health problems congruent with obesity, e.g., hypercholesterolemia, HTN, and DM $[1,9]$. Recently, overweight and obesity have been shown to be related to low vitamin D status. Over 840 million people suffer from VDD [10], either due to a low vitamin (ergocalciferol) intake, with malabsorption syndrome [11], or limited exposure to sunlight, e.g., as in the use of sunscreen.

Vitamin D plays a role in a multitude of metabolic processes are established. For instance, Vitamin D receptor (VDR) and $1 \alpha$-hydroxylase enzyme, which catalyzes the conversion of calcidiol [25(OH)D] to calcitriol [1,25(OH)2D] which is the activated vitamin D were found in more than 40 human cell types [11]. Thereby, 


\section{Current Research in Diabetes \& Obesity Journal}

VD has been linked with the risk of "metabolic syndrome" (central obesity, hyperglycemia, HTN, and atherogenic dyslipidemia) [12].

\section{Obesity and VD mechanisms}

A temporal relationship between $n$ increased body fat $(\mathrm{BF})$ and low circulating 25(OH)D level and resulting impaired metabolic pathways of VD has been suggested [13]. Whether VDD may facilitate the development of obesity, and hence a maintained vitamin D level could be protective against obesity and increased fat mass (FM) in risky people has been argued $[14,15]$. Due to the widespread prevalence of obesity alongside with unhealthy diet and physical inactivity (PIA), large-scale experiments to observe diet history, outcomes, and directionality of the relationship between VDD and obesity are scarce. Leblanc et al. [16] however, could link vitamin D levels with lower weight gain in a study on 9,704 women aged $\geq 65$, higher and concluded that low vitamin D may predispose to fat accumulation, and vice versa. Using genetic markers as instrumental variables in a bi-directional Mendelian randomization analysis [10], it was found that higher BMI levels led to lower serum 25(OH)D levels. Although the effect of a lower $25(\mathrm{OH}) \mathrm{D}$ on increasing BMI was likely to be small, it has been emphasized that mass interventions to reduce BMI were expected to decrease VDD prevalence [10].

In a study by Kremer et al. [15] to examine the relationship between $25(\mathrm{OH}) \mathrm{D}, \mathrm{BF}$, and bone structure at the time of peak bone mass in California, 90 post-pubertal women 16-22, 59\% of subjects were $25(\mathrm{OH}) \mathrm{D}$ insufficient $(\leq 29 \mathrm{ng} / \mathrm{ml})$, and $41 \%$ were sufficient ( $\geq 30 \mathrm{ng} / \mathrm{ml}$ ). A strong inverse relationship between serum 25(OH)D and visceral adipose tissue (VAT), measured by CT scan and dual-energy X-ray absorptiometry (DEXA) values of BF were found. Further, weight, body mass (BM), and adiposity were lower in women with normal 25(OH)D - than those with insufficient levels.

In the older-age population [16], women with low circulating vitamin D levels were liable to add weight compared with those with adequate levels of the vitamin; the longer VDD the greater likelihood to build-up weight [16]. In the presence of such growing belief that vitamin D could play a role in regulating VAT, Leblanc et al. [17] conducted two parallel trials to study the effect of Ca-D-fortified orange juice (OJ) and regular OJ on VAT reduction using regular vs. reduced-energy (lite) OJ. In the regular OJ tri$\mathrm{al}$, the reduction of VAT was greater among the CaD group than in the control group. In the lite OJ trial, the reduction of VAT was significantly greater in the CaD group than in controls (after controlling for baseline VAT). The effect of calcium/vitamin D on VAT remained highly significant when the results of both trials were combined. It may well be suggested that vitamin D and/or calcium supplementation contribute to a beneficial reduction of VAT.

As far as other VDD-related metabolic drawbacks, the risks of CVD, DM, HTN and dyslipidemia have been linked with VDD [1822]. On the other hand, adipokines play a role in the homeostatic mechanisms of food intake, glucose and lipid metabolism, vascu- lar remodeling, and insulin action [21-23]. Additionally, hypertrophy of adipocytes is connected with increased synthesis of pro-inflammatory mediators, such as tumor necrosis (TNF)- $\alpha$ factor and some interleukin (IL) classes (IL-1, IL-6) [21,24]. Particularly leptin is a circulating hormone produced primarily by adipose tissue [21] and its biosynthesis is operated by leptin gene (OB) located on the 7th chromosome. Leptin synthesis is stimulated by insulin, glucocorticosteroids, TNF- $\alpha$ and estrogens, and inhibited by free fatty acids (FFAs) and growth hormone [21]. Once secreted into the bloodstream, leptin is able to regulate food intake and metabolism and decrease appetite $[21,23,25]$. The concentration of circulating leptin increases with FM and decreases with BM reduction [21]. Vitamin D, in turn, supports leptin signaling so that in VDD states interrupted signaling leads to disrupted fullness sensation mechanism.

Given the fat-soluble nature of VD (fat acts as a "sink" by collecting it); obese patients are more prone to developing VDD symptoms than the non-obese [26]. Tests involving obesity-VDD symptoms include serum vitamin D level (25[OH[D); plasma parathyroid hormone (PTH) level; serum calcium, and fasting plasma glucose (FPG) levels. Vitamin D insufficiency may be defined as 10 to $<19.9 \mathrm{ng} / \mathrm{ml}$. A serum concentration of $25(\mathrm{OH}) \mathrm{D} \geq 20 \mathrm{ng} / \mathrm{ml}$ is considered as adequate vitamin D level.

Regarding treatment strategies, vitamin D 40,000 units/wk for 7 weeks followed by 4,000 units/d for 10 weeks and then followed by 800-2000 units maintenance dose daily is recommended [27], for a target VDD point $>30 \mathrm{ng} / \mathrm{ml}$. Exposure to sun rays, avoiding the use of sunscreens and a diet wit satisfactory VD content to maintain adequate circulating vitamin D level are warranted. For obesity, abiding by an adjusted weight loss program in line a balance between calorie intake and calorie expenditure through PA is needed. Bariatric surgical intervention for treating morbid obesity, especially controlling the associated comorbidities, such as CVD, sleep apnea, osteoarthritis, is a further step to follow. Dietary supplementation (vitamins B12 and D, Zn, Fe) after surgery is usually indicated $[28,29]$.

\section{Conclusion}

In conclusion, both obesity and VDD are two widespread chronic diseases of today's communities. Both conditions are interrelated; first, obesity is risk for VDD, especially in high risk people, such as old women and people with multiple chronic comorbidities. On the other hand, a reduced serum 25(OH)D level may be associated with enhanced CT signals of VF, and also the abdominal fat mass may be reduced with 25(OH)D level normalization. Obesity and VDD have a wide scope of complications, some of which are shared by the two ailments. Both obesity and VDD are directly linked to lifestyle, the modification of which plays a significant role in controlling of these conditions. An early detection of obesity and related risks as well as impaired VD levels through community screening would are cost-effective. Despite a remarkable success has been achieved in the research of fat tissue 
volume and distribution and impaired circulating VD, large-scale experimentation on mechanisms pertinent with vitamin D and BF distribution should be considered.

\section{References}

1. (2014) American Heart Association (AHA). Obesity Information.

2. Leblanc ES, Rizzo JH, Pedula KL, Ensrud KE, Cauley J, et al. (2012) Associations between 25-hydroxyvitamin $\mathrm{D}$ and weight gain in elderly women. Journal of Women Health 21(10): 1066-1073.

3. (2017) World Health organization (WHO). Global Health Observatory (GHO) data. Overweight and obesity.

4. (2016) 2 Obesity and overweight. Fact sheet.

5. (2016) Obesity and overweight. Fact sheet.

6. Ahmad N, Adam SA, Nawi AM, Hassan MR, Ghazi HF (2016) Abdominal Obesity Indicators: Waist Circumference or Waist-to-hip Ratio in Malaysian Adults Population. Int J Prev Med 7: 82.

7. Tanamas SK, Ng WL, Backholer K, Hodge A, Zimmet PZ, et al. (2016) Quantifying the proportion of deaths due to body mass index- and waist circumference-defined obesity. Obesity (Silver Spring) 24(3): 735-742.

8. Qin X, Zhang Y, Cai Y, He M, Sun L, et al. (2012) Prevalence of obesity, abdominal obesity and associated factors in hypertensive adults aged 45-75 years. Clin Nutr 32(3): 361-367.

9. Lim SL, Bruce AS (2015) Prospect theory and body mass: characterizing psychological parameters for weight-related risk attitudes and weight-gain aversion. Front Psychol 6: 330.

10. Lee EB (2011) Obesity, leptin, and Alzheimer's disease. Ann N Y Acad Sci 1243: 15-29.

11. Vimaleswaran KS, Berry DJ, Lu C, Tikkanen E, Pilz S, et al. (2013) Causal relationship between obesity and vitamin D status: bi-directional Mendelian randomization analysis of multiple cohorts. PLoS Med 10(2): e1001383.

12. Alam J, Jan SS (2016) Association between vitamin d deficiency and depressive illness in adult population. J Med Sci 24(4): 2007-2010.

13. Srikanthan K, Feyh A, Visweshwar H, Shapiro JI, Sodhi K (2016) Systematic Review of Metabolic Syndrome Biomarkers: A Panel for Early Detection, Management, and Risk Stratification in the West Virginian Population. Int J Med Sci 13(1): 25-38.

14. McGill AT, Stewart JM, Lithander FE, Strik CM, Poppitt SD (2008) Relationships of low serum vitamin D3 with anthropometry and markers of the metabolic syndrome and diabetes in overweight and obesity. Nutrition Journal 7: 1-5.
15. Kremer R, Campbell PP, Reinhardt T, Gilsanz V (2009) Vitamin D Status and Its Relationship to Body Fat, Final Height, and Peak Bone Mass in Young Women. J Clin Endocrinol Metab 94(1): 67-73.

16. LeBlanc ES, Rizzo JH, Pedula KL, Ensrud KE, Cauley J, et al. (2012) Associations Between 25-Hydroxyvitamin D and Weight Gain in Elderly Women. Journal of Women's Health 21(10): 1066-1073.

17. Leblanc ES, Rizzo JH, Pedula KL, Ensrud KE, Cauley J, et al. (2012) Associations between 25-hydroxyvitamin D and weight gain in elderly women. J Womens Health (Larchmt) 21(10): 1066-1073.

18. Rosenblum JL, Castro VM, Moore CE, Kaplan LM (2012) Calcium and vitamin D supplementation is associated with decreased abdominal visceral adipose tissue in overweight and obese adults. Am J Clin Nutr 95(1): 101-108.

19. Ding C, Gao D, Wilding J, Trayhurn P, Bing C (2012) Vitamin D signalling in adipose tissue. Br J Nutr 108(11): 1915-1923.

20. Frankiewicz T (2011) Vitamin D supplementation-is it only osteoprotection? Prz Menopauz 4: 328-333.

21. Gannagé-Yared MH, Chedid R, Khalife S, Azzi E, Zoghbi F, et al. (2009) Vitamin $D$ in relation to metabolic risk factors, insulin sensitivity and adiponectin in a young Middle-Eastern population. J Endocrinol 160(6): 965-971.

22. Skowrońska B, Fichna M, Fichna P (2005) The role of adipose tissue in endocrine system. Endokrynol Otyłość 1: 21-29.

23. Ulutas O, Taskapan H, Taskapan MC, Temel I (2013) Vitamin D deficiency, insulin resistance, serum adipokine, and leptin levels in peritoneal dialysis patients. Int Urol Nephrol 45(3): 879-884.

24. de Luis DA, Soto GD, Conde R, Izaola O, de la Fuente B (2012) Relation of leptin and adiponectin with cardiovascular risk factors, intact parathormone, and vitamin D levels in patients with primary hyperparathyroidism. J Clin Lab Anal 26(5): 398-402.

25. Lira FS, Rosa JC, Cunha CA, Ribeiro EB, do Nascimento CO (2011) Supplementing alpha-tocopherol (vitamin E) and vitamin D3 in high fat diet decrease IL-6 production in murine epididymal adipose tissue and 3T3-L1 adipocytes following LPS stimulation. Lipids Health Dis 10: 37.

26. Casanueva FF, Diéguez C (1999) Neuroendocrine regulation and actions of leptin. Front Neuroendocrinol 20(4): 317-363.

27. (2016) National Institute of Health (NIH). Vitamin D. Fact sheet for health professionals.

28. (2016) New Therapies Subgroup. Treatment of Vitamin D Deficiency and Insufficiency in Adults.

29. American Society for Metabolic and Bariatric Surgery. Who is a Candidate for Bariatric Surgery.

\begin{tabular}{|l|}
\multicolumn{1}{|c|}{ Your next submission with Juniper Publishers } \\
will reach you the below assets \\
- Quality Editorial service \\
- Swift Peer Review \\
- Reprints availability \\
- E-prints Service \\
- Manuscript Podcast for convenient understanding \\
- Global attainment for your research \\
- Manuscript accessibility in different formats \\
( Pdf, E-pub, Full Text, Audio) \\
- Unceasing customer service \\
Track the below URL for one-step submission \\
https://juniperpublishers.com/online-submission.php
\end{tabular}

